\title{
DYNAMIC IN VITRO CALCIFICATION OF BIOPROSTHETIC PORCINE VALVES: EVIDENCE OF APATITE CRYSTALLIZATION
}

Elena Pettenazzo, $\mathrm{PhD}^{\mathrm{a}}$

Michael Deiwick, $\mathrm{MD}^{\mathrm{b}}$

Gaetano Thiene, $\mathrm{MD}^{\mathrm{a}}$

Gianmario Molin, BSc ${ }^{c}$

Birgit Glasmacher, $\mathrm{PhD}^{\mathrm{d}}$

Fedora Martignago, $\mathrm{BSc}^{\mathrm{c}}$

Tomaso Bottio, MD

Helmut Reul, $\mathrm{PhD}^{\mathrm{d}}$

Marialuisa Valente, $\mathrm{MD}^{\mathrm{a}}$

For related editorial, see p. 428.
Objective: Calcification is the most important cause of structural deterioration of glutaraldehyde-fixed bioprosthetic valves. Devitalization of tissue favors calcium deposits in the shape of apatite crystals. Host factors influence the extent and progression of calcification, but the phenomenon can also occur in vitro in the absence of a viable milieu. Whether calcific deposits obtained in vitro are similar to those found in vivo is unknown.

Methods: Four porcine frame-mounted bioprostheses (St Jude Medical Bioimplant; St Jude Medical, Inc, St Paul, Minn) were tested in vitro by using a pulsatile accelerated calcification testing device at a frequency of 300 cycles per minute at $37^{\circ} \mathrm{C}$ for $19 \times 10^{6}$ cycles with a rapid synthetic calcification solution (final product [calcium $\times$ phosphate], $130 \mathrm{mg} / \mathrm{dL}^{2}$ ). Three of the same type of xenografts explanted from human subjects because of calcific failure (time in place, $108 \pm 25.63 \mathrm{mo}$ ) served as control grafts. Each sample underwent gross and x-ray examination, histology, transmission and scanning electron microscopy, atomic absorption spectroscopy, electron microprobe analysis, and x-ray powder diffraction methods.

Results: All in vitro bioprostheses were heavily calcific, with intrinsic Von Kossa stain-positive deposits and a mean calcium content of $205.285 \pm$ $64.87 \mathrm{mg} / \mathrm{g}$ dry weight. At transmission electron microscopy, nuclei of calcification involved mostly collagen fibers and interfibrillar spaces and, more rarely, cell debris and nuclei. Electron microprobe analysis showed a $\mathrm{Ca} / \mathrm{P}$ atoms ratio of 4.5:3, a value intermediate between hydroxyapatite and its precursor, octacalciumphosphate. X-ray powder diffraction showed a wellseparated and sharp peak, which is typical of hydroxyapatite. Aggregates of plate-like crystals up to $8 \mu \mathrm{m}$ in size were observed at scanning electron microscopy, with a typical tabular hexagonal shape consistent with apatite. The morphologic and chemical findings in human explants were similar.

Conclusions: Intrinsic calcification of glutaraldehyde-fixed porcine valves was induced in vitro. Electron microprobe analysis and $\mathrm{x}$-ray powder diffraction findings were in keeping with apatite crystallization, such as that occurring in valve xenografts implanted in vivo. The model may be of value to accelerate the screening of anticalcific agents and may reduce the need for animal experiments. (J Thorac Cardiovasc Surg 2001;121:500-9)
From the Departments of Pathology ${ }^{\mathrm{a}}$ and Mineralogy \& Petrology, ${ }^{\mathrm{c}}$ University of Padua Medical School, Padua, Italy; the Department of Cardiothoracic Surgery, ${ }^{\mathrm{b}}$ Münster, Germany; and the Helmholtz-Institute for Biomedical Engineering, Aachen, Germany.

This study was supported by the Istituto Superiore di Sanità, Progetto "Protesi Endovascolari," by MURST, and by the Veneto Regione, Rome and Venice, Italy.

Copyright (C) 2001 by The American Association for Thoracic Surgery

0022-5223/2001 $\$ 35.00+0 \quad \mathbf{1 2 / 1 / 1 1 2 4 6 4}$

doi: $10.1067 / \mathrm{mtc} .2001 .112464$ alcification is the most important cause of structural deterioration of glutaraldehyde-fixed bioprosthetic valves. ${ }^{1,2}$ Glutaraldehyde treatment, tissue devitalization, and mechanical stress have been postulated to promote calcification when the bioprostheses are implanted in vivo, either in the orthotopic or subdermal position. ${ }^{3-8}$ The extent and progression of calcification depends also on host factors, such as age, renal function, pregnancy, and other unknown determinants, but host-graft interaction is not essential for mineralization 
development. In fact, calcification can be reproduced in vitro by using pulsatile testing devices with an appropriate solution. ${ }^{9,10}$ The objective of this investigation was to provide evidence that calcification induced in vitro is similar to that occurring spontaneously in vivo.

\section{Material and methods}

Four porcine frame-mounted bioprostheses (St Jude Medical Bioimplant; St Jude Medical, Inc, St Paul, Minn) were tested in vitro with a pulsatile accelerated calcification testing device (Fig 1). A rapid synthetic calcification fluid was developed by means of modification of the solution according to the method of Starcher and Urry. ${ }^{11}$ In our preliminary studies, ${ }^{9}$ isolated leaflets were placed in different solutions without mechanical stress to find the ideal solution. Eventually, a solution was chosen with a $\mathrm{pH}$ of 7.4 and a final product (calcium $\times$ phosphate) of $130 \mathrm{mg} / \mathrm{dL}^{2}$, which is comparable with that of bovine plasma solution (not suitable for prolonged testing because of infection risk and cost). Calcification was negligible without mechanical stress. The pulsatile accelerated testing device was constructed according to the standards published by the US Food and Drug Administration (FDA). ${ }^{12}$ Although not FDA approved, our test device is even more sophisticated with respect to special requirements for bioprostheses of FDA guidelines because it allows full opening and closing of the leaflets. The device is made of 10 separate test chambers containing the valve within the calcification fluid. All test chambers were sterilized with ethylene oxide. Each valve was mounted within a separate compartment and tested at frequencies of 300 cycles per minute at $37^{\circ} \mathrm{C}$. Preliminary studies allowed the choice of test frequency, number of cycles, and test duration. ${ }^{9,10}$ Test frequency was chosen to meet one demand, namely, acceleration of testing by preserving full opening and closing of valve leaflets. The test duration and number of cycles were established by means of a weekly inspection of valve calcification through gross and $\mathrm{x}$-ray examination during the test period. Simultaneous pressure monitoring on both sides of the bioprostheses was performed to assess occurrence of valve stenosis and incompetence. Further details are described in previous articles. 9,10 The pressure difference across the valves was adjusted at $120 \mathrm{~mm} \mathrm{Hg}$. The calcification medium was changed weekly, and depletion of calcium and phosphate was measured by atomic absorption spectroscopy for each compartment as indirect evidence of calcium and phosphate precipitation into the bioprosthetic tissue. At the end of every test week, the mean of calcium concentration in the test fluid varied from 1.07 to $2.03 \mathrm{mmol} / \mathrm{L}$, and the phosphate concentration varied from 1.12 to $2.33 \mathrm{mmol} / \mathrm{L}$. Precipitation on the walls of the chamber was excluded. The test was terminated after $19 \times 10^{6}$ cycles. Each specimen underwent gross and mammography x-ray examination, and calcium deposits were assessed semiquantitatively as follows: score 0 , none; score 1 , focal, pinpoint, $<1 \mathrm{~mm}$; score 2 , focal, $>1 \mathrm{~mm}$, or multiple pinpoint; score 3 , multiple, large; and score 4 , massive. ${ }^{1}$ For histology, samples from each cusp were formalin fixed and paraffin embedded; 5- to 7- $\mu \mathrm{m}$ thick sections were stained with hematoxylin and eosin, Weigert-Van Gieson, and Heidenhein tricrome stains and Von Kossa counterstained with neutral red. For transmission electron microscopy (TEM), samples were fixed in Karnovsky solution, postfixed in $1 \%$ osmium tetroxide, dehydrated in alcohol, and embedded in epoxy resin. Semithin sections were stained with $0.1 \%$ toluidine blue for light microscopic examination. Ultrathin sections were stained with uranyl acetate and lead citrate and examined with a Hitachi H-7000 microscope (Hitachi, Ltd, Tokyo, Japan). For scanning electron microscopy, samples of each specimen were dehydrated through a graded ethanol series and in amyl acetate and finally dehydrated at the critical point drying with carbon dioxide. The specimen was then coated with gold-platinum film and observed with a Philips XL30 TMP electron microscope (Philips Electronics N.V., Eindhoven The Netherlands). For assessment of calcium content, samples of bioprostheses were dried to a constant weight in a desiccator oven and incubated with $\mathrm{HNO}_{3}(0.75 \mathrm{~mol} / \mathrm{L})$ at $68^{\circ} \mathrm{C}$ for 15 hours. After centrifugation at $2500 \mathrm{~g}$, the fluid removed was diluted, and the calcium content was determined by means of atomic absorption spectroscopy. Elemental concentrations were expressed throughout as milligrams per gram of dry tissue weight. Fragments of the 4 in vitro tested bioprostheses were submitted to x-ray powder diffraction analysis (XRPD). For the analysis, we used a Philips PW 3710 diffractometre operating with Bragg-Brentano geometry. Experimental conditions were $40 \mathrm{kV}$ and $20 \mathrm{~mA}$, with $\mathrm{CuK} \alpha_{1,2}$ radiation; data collections were carried out by scanning the 2 -range from $24^{\circ}$ to $55^{\circ}$ and using the step-by-step method with a step width of $0.02^{\circ}$ and a counting time of 2 seconds per step. After XRPD investigation, a fragment was then embedded in epoxy resin, cut, and polished. The sample, coated with a $200-\AA$ layer of carbon, was submitted to a CAMECA-CAMEBAX electron microprobe (electron microprobe analysis [EMPA]) (CAMECA, Paris, France) to study the chemical composition of mineralized areas. Operating conditions of the instrument, equipped with 4 wavelength dispersive spectroscopy $\mathrm{x}$-ray spectrometers, were $15 \mathrm{kV}$ and $15 \mathrm{nA}$ sample current and counting time of $10 \mathrm{sec}-$ onds at the peak and 10 seconds at the background. Analyses were performed against synthetic end-member mineral standards. X-ray counts were converted into oxide weight percentages by using the PAP correction program supplied by CAMECA. Quantitative chemical analysis was calculated on the average of 10 single spots and atoms per formula unit on the basis of 12 oxygen atoms.

Three porcine St Jude Medical Bioimplant xenografts implanted in human subjects as mitral valve substitutes and explanted because of calcific structural valve deterioration (time in place, $108 \pm 25.63$ months) were used as control grafts and submitted to the same investigation protocol. This model of porcine bioprostheses was selected because it was the same as used in vitro and because there was no calcium mitigation treatment.

\section{Results}

All in vitro tested bioprostheses appeared heavily calcified at gross and x-ray examination (score, 4 each), either on the cusp body or the commissures; two cases 


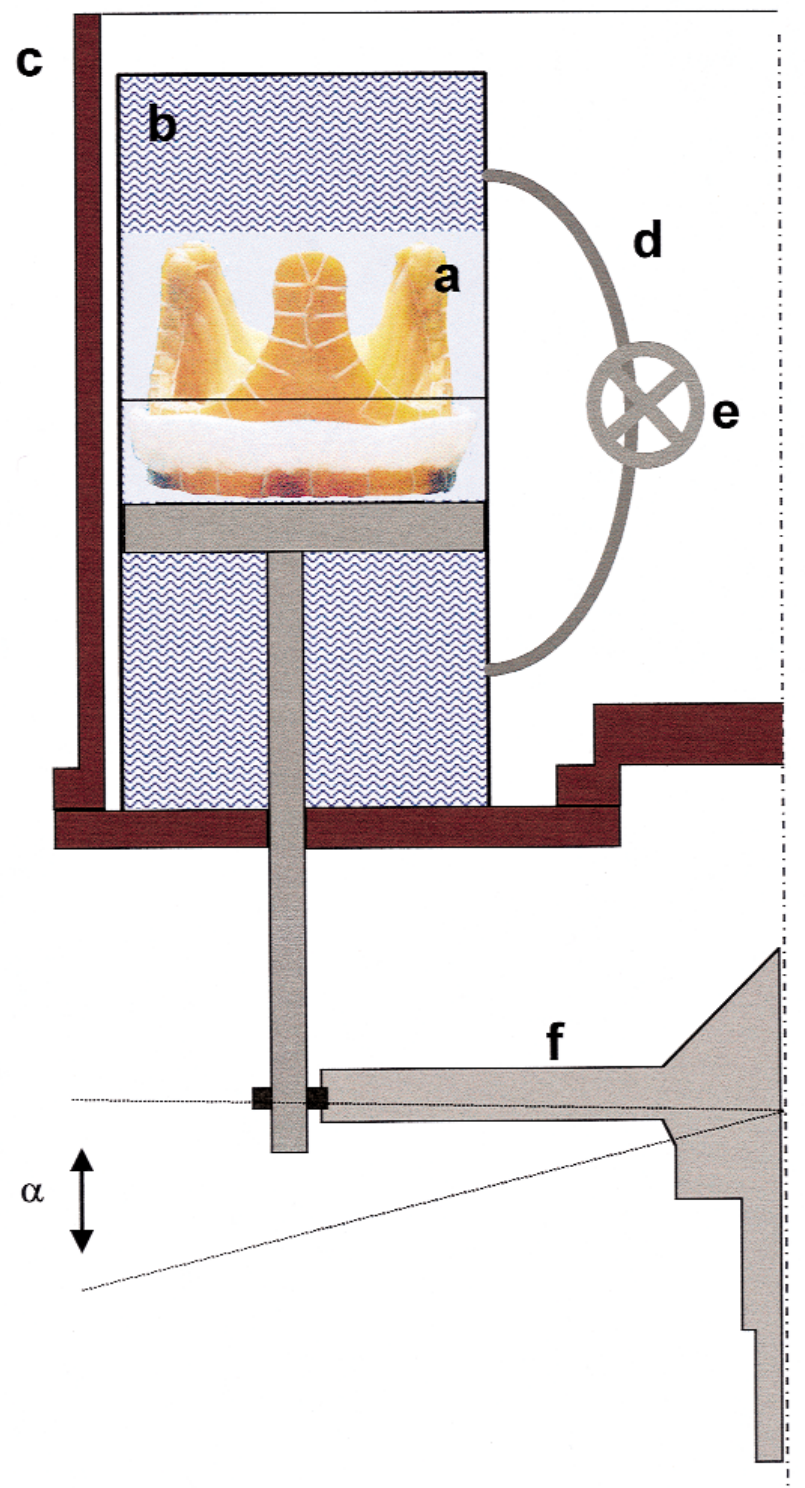

Fig 1. Pulsatile accelerated testing device. $a$, Mounted bioprosthetic on the cylinder; $b$, test chamber containing the calcification fluid; $c$, housing; $d$, bypass; $e$, choke; $f$, rotating swash plate with adjustment of plate inclination; $\alpha$, angle of inclination.

presented with eggshell cusp fragmentation (Table I and Fig 2, $A$ and $B$ ). At atomic absorption spectroscopy, calcium content ranged from 111.11 to $259.66 \mathrm{mg} / \mathrm{g}$ dry weight (mean, $205.285 \pm 64.87 \mathrm{mg} / \mathrm{g}$ dry weight; Table I). At histology, Von Kossa stain disclosed intrinsic calcification, both nodular and laminar, involving either the fibrosa or the spongiosa (Fig 3, $A$ and $B$ ); calcification regularly involved the muscle shelf of the right cusp. Films of calcific deposits on the cusp surface were rare and negligible in amount. Calcium depositions were also visible in the aortic wall tunica media on smooth muscle cells (Fig 3, $C$ and $D$ ). At TEM, cal- cification involved mostly microstructural components, such as collagen fibrils and interfibrillar spaces, and, more rarely, cells, including nuclei and cytoplasm organelles and debris; plate-like calcific deposits were also observed (Fig 4). XRPD technique disclosed the presence of diffraction peaks, which are in keeping with apatite $\mathrm{Ca}_{5}\left(\mathrm{PO}_{4}\right)_{3}(\mathrm{OH}, \mathrm{Cl})$ (Fig 5, A). Because of the large amount of organic tissue in the samples, the background radiation was particularly high. EMPA analysis detected calcium phosphate, with a $\mathrm{Ca} / \mathrm{P}$ atoms ratio of 4.5:3 (Table II, $A$ and $B$ ), a value intermediate between that of apatite (5:3) and octacalci- 

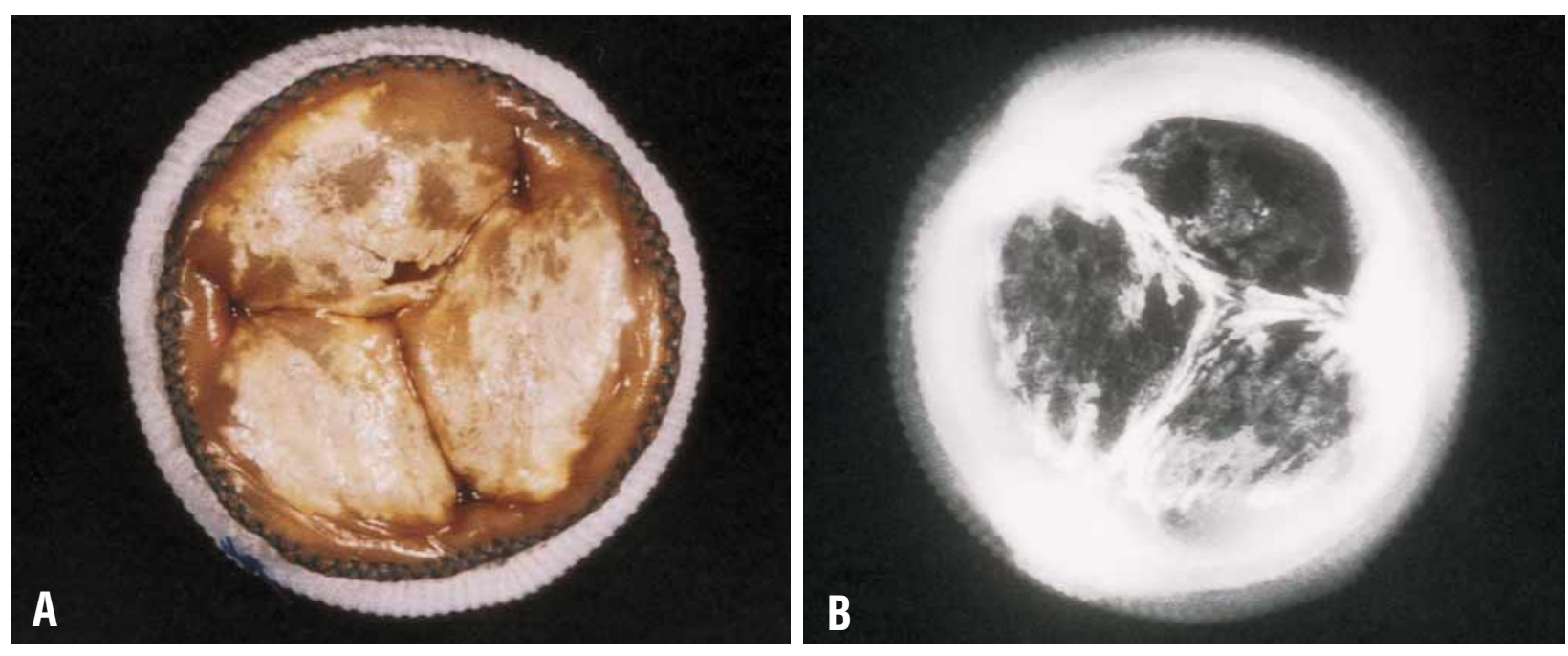

Fig 2. Case 4. A, Gross view: diffuse calcium deposition with eggshell cusp fragmentation. B, X-ray view: massive mineralization (score 4).

umphosphate (4:3), a metastable precursor of apatite, with the formula $\mathrm{Ca}_{4} \mathrm{H}\left(\mathrm{PO}_{4}\right)_{3} 2.5 \mathrm{H}_{2} \mathrm{O}$ and a similar XRPD pattern. Scanning electron microscopy investigation showed the presence of euhedral aggregates of exhagonal tabular crystals up to about $8 \mu \mathrm{m}$ in size, showing well-developed basal pinacoids (Fig 5, B), a clear-cut morphologic finding consistent with hexagonal habitus of apatite.

The 3 human explants failed because of incompetence caused by calcific commissural tearing. At gross inspection and x-ray examination, massive calcification (score, 4 each) was detected. Histology disclosed intrinsic nodular calcific deposits, which, at TEM, resulted in involved collagen fibers and, more rarely, cell debris (Figs 6 and 7). At atomic absorption spectroscopy, a mean mineralization value of $106.03 \pm 7.02 \mathrm{mg} / \mathrm{g}$ dry weight (ranging from 101.07 to $168.94 \mathrm{mg} / \mathrm{g}$ ) was found. The XRPD showed sharp picks, which is in keeping with well-crystallized apatite precipitates (Fig 8).

\section{Discussion}

Calcification of biologic tissues occurs in 2 different phases, namely, nucleation and propagation. ${ }^{13}$ Nucleation is very critical because in biologic fluids calcium and phosphate are insufficient to allow a spontaneous precipitation of hydroxyapatite from their preliminary compounds, namely, amorphous calcium phosphate and octacalciumphosphate. At the site of calcification, a localized microenvironment occurs in which concentrations of calcium and phosphate are elevated to the point of apatite precipitation. During bone formation, this process is mainly due to the action of energy-
Table I. $X$-ray scores and calcium contents

\begin{tabular}{lcc}
\hline Sample No. & $X$-ray & Ca content $(\mathrm{mg} / \mathrm{g} \text { dry weight })^{*}$ \\
\hline 1 & 4 & 111.11 \\
2 & 4 & 223.16 \\
3 & 4 & 259.66 \\
4 & 4 & 227.21 \\
\hline
\end{tabular}

*Mean: $205.285 \pm 64.87 \mathrm{mg} / \mathrm{g}$.

requiring phosphatase concentrated in the matrix vesicles. Instead, a non-energy-requiring $\mathrm{Ca}^{2+}$ trap has been postulated to occur in cartilage ossification as a result of phosphatidyl-serine and other phospholipids through the formation of calcium-phospholipidic complexes, which can also nucleate hydroxyapatite from metastable calcium phosphate solution. ${ }^{14,15}$ It has been postulated that octacalciumphosphate is a preliminary compound of hydroxyapatite in cartilage mineralization. This non-energy-requiring process is most probably responsible for bioprosthetic calcification, in which cells are devitalized by glutaraldehyde treatment. In fact, viable cells have an approximately 10,000-fold gradient of calcium from outside to inside $\left(10^{-3}\right.$ vs $10^{-7}$ $\mathrm{mol} / \mathrm{L}$ ). Low intracellular calcium concentrations are maintained by energy-dependent pumps at the cell membranes. In cells rendered nonviable by glutaraldehyde fixation, calcium pumps are impaired, and calcium passively diffuses into the cytoplasm and reacts with phospholipids of cell and organelle membranes. ${ }^{5,16}$ Once nucleation has occurred, the concentration of calcium and phosphate in metastable fluids is sufficient for crystal propagation. Calcification of bio- 

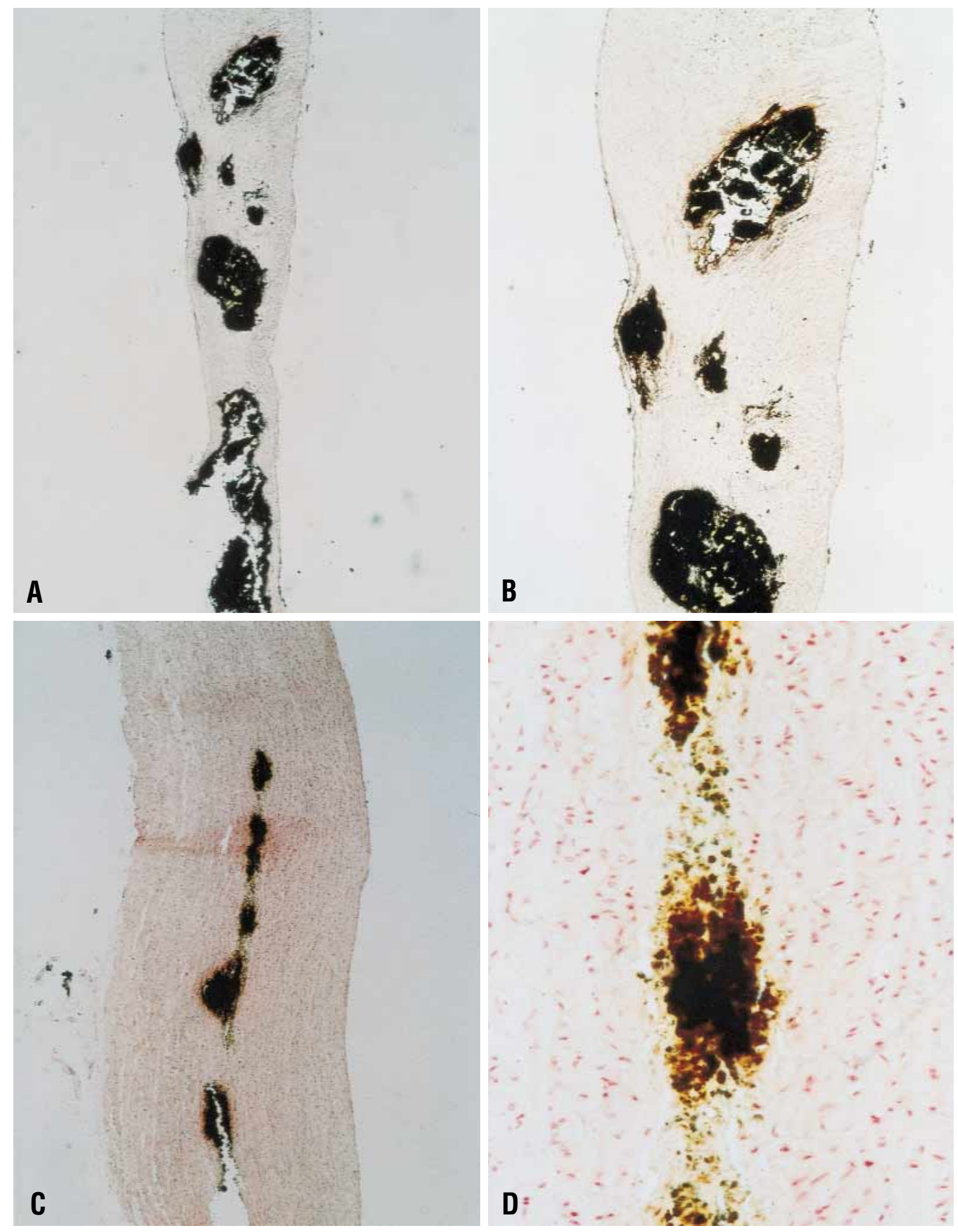

Fig 3. Case 4. A, Cuspal intrinsic calcium deposits at histologic examination. (Von Kossa stain; original magnification, 12×.) B, Higher magnification of $\mathbf{A}$. (Von Kossa stain; original magnification, 36×.) $\mathbf{C}$, Calcium deposits in the aortic wall tunica media. (Von Kossa stain; original magnification, 36×.) D, Higher magnification of $\mathbf{C}$. Calcification involves smooth muscle cells. (Von Kossa stain; original magnification, 240×.) 


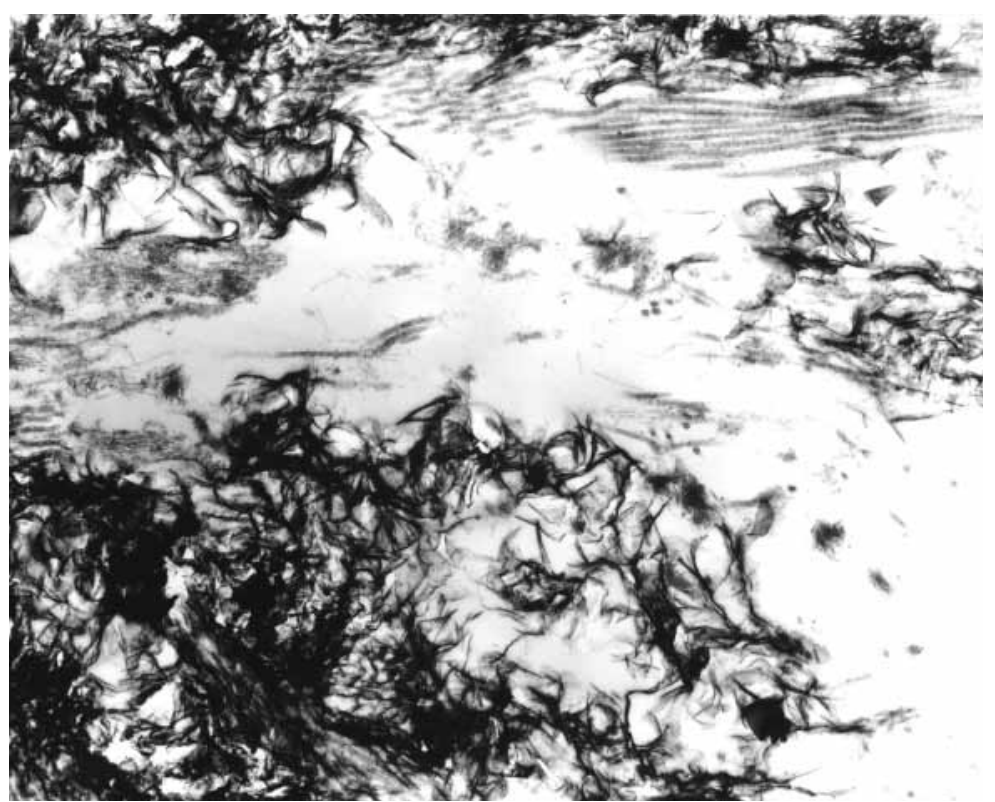

Fig 4. Case 3. TEM with calcification involving collagen fibers. Note the plate-like features. (Original magnification, $24,000 \times$.)

Table IIA. EMPA: Analysis in oxides, \% (averaged on 10-spot analysis)

\begin{tabular}{cccccccc}
\hline & $\mathrm{MgO}$ & $\mathrm{Al}_{2} \mathrm{O}_{3}$ & $\mathrm{P}_{2} \mathrm{O}_{5}$ & $\mathrm{SO}_{3}$ & $\mathrm{Cl}$ & $\mathrm{CaO}$ & Oxides $_{\text {tot }}$ \\
\hline Mean $\pm \mathrm{SD}$ & $0.03 \pm 0.03$ & $0.02 \pm 0.02$ & $35.68 \pm 4.11$ & $0.05 \pm 0.05$ & $0.44 \pm 0.38$ & $41.14 \pm 5.04$ & $77.36 \pm 8.58$ \\
\hline
\end{tabular}

${ }^{*} \mathrm{Cl}$ is expressed as hypothetic $\mathrm{Cl}_{2} \mathrm{O}$.

Table IIB. EMPA: Atoms per formula unit calculated on the basis of the 12 oxygen atoms $\left(\mathrm{Ca}_{5}\left[\mathrm{PO}_{4}\right]_{3}[\mathrm{OH}]\right)$

\begin{tabular}{cccccccc}
\hline & $M g$ & $A l$ & $P$ & $S$ & $C l$ & $C a$ & Total cations \\
\hline Mean \pm SD & $0.004 \pm 0.004$ & $0.002 \pm 0.003$ & $3.020 \pm 0.054$ & $0.004 \pm 0.004$ & $0.056 \pm 0.056$ & $4.463 \pm 0.138$ & $7.489 \pm 0.083$
\end{tabular}

prostheses implanted in vivo, which at first occurs on cell membranes and then involves collagen fibers and interfibrillar spaces, ${ }^{3,4}$ has been proven to consist of hydroxyapatite.

Calcification has been reproduced in vitro. Bernacca and colleagues, ${ }^{17}$ studying bovine pericardial valves by means of an in vitro fatigue tester method with various test media, including bovine plasma, found large calcium deposits at histologic examination. Nevertheless, it was not clear whether this calcium deposition was a generalized precipitation limited to the biomaterial surfaces (extrinsic calcification) or involved structural bioprosthetic components (intrinsic calcification). ${ }^{18}$ Deiwick, ${ }^{9}$ Glasmacher, ${ }^{10}$ and their colleagues developed a protocol for accelerated in vitro valve calcification and were able to reproduce massive calcification in vitro. They demonstrated, by means of weekly x-ray examination, that mineralization was initially minimal and then increased in an exponential way. By using holographic interferometry, they demonstrated a strong correlation between holographic anomalies and bioprosthetic calcification. This protocol was applied also to the porcine bioprostheses herein investigated in vitro, with the purpose of verifying whether calcification was structurally and biochemically similar to that occurring in bioprostheses implanted in vivo. We found massive and extensive calcification both at gross and $\mathrm{x}$-ray examination. Histologic and ultrastructural features were quite similar to those observed in the same type of porcine bioprostheses 


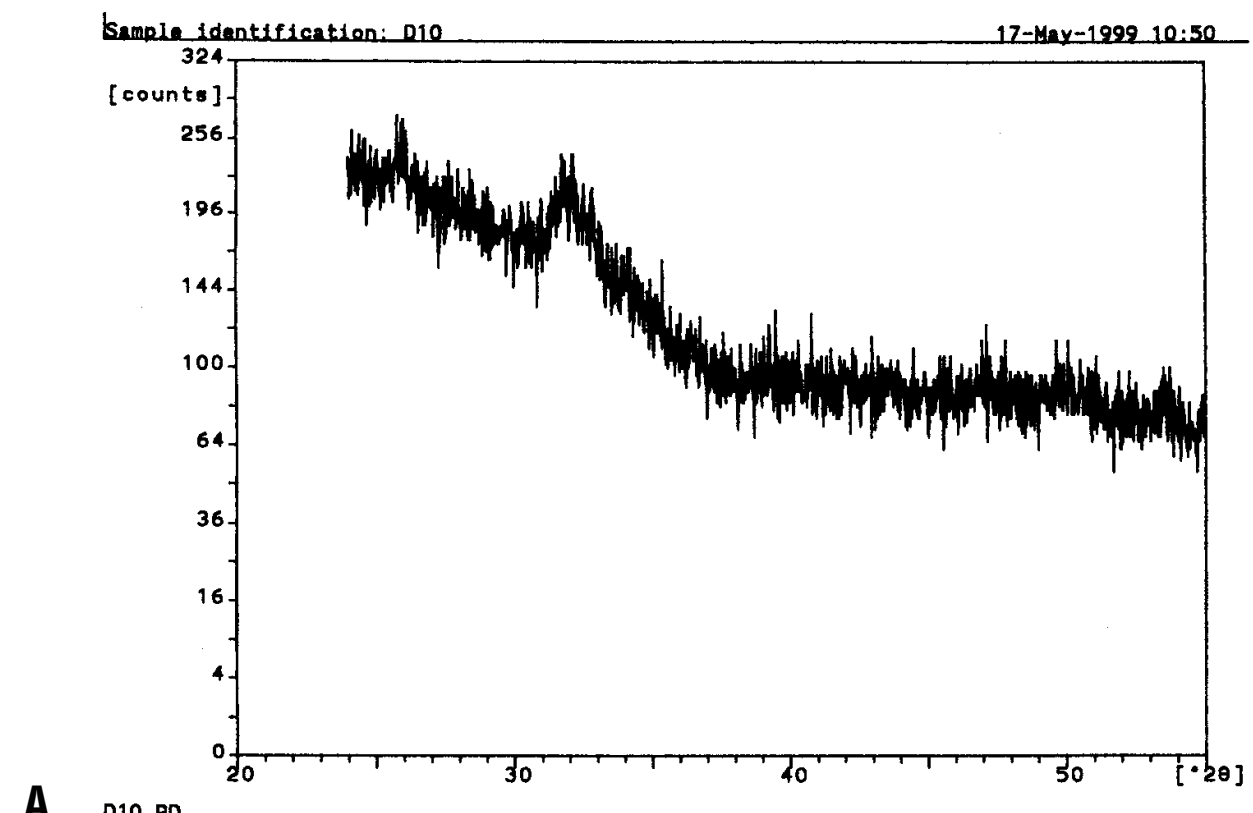

A

D10.RD

B

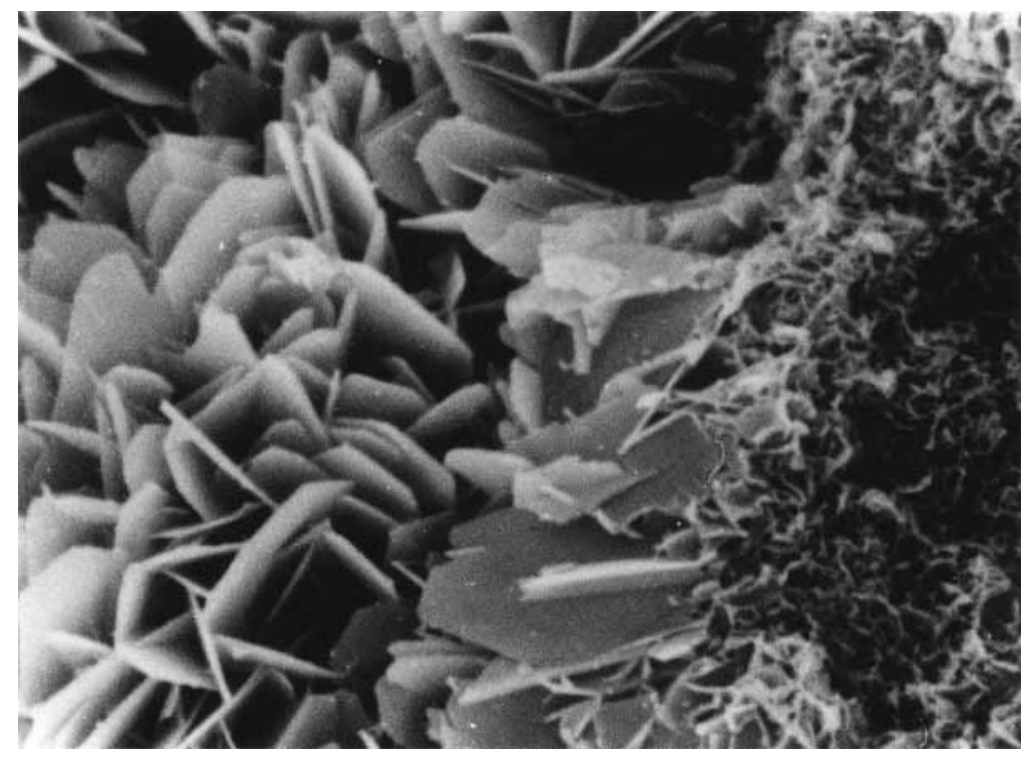

Fig 5. Case 1. A, XRPD $\left(\mathrm{CuK} \alpha_{1,2}\right)$ patterns of an in vitro tested sample in the $2 \theta$ range of $24^{\circ}$ to $55^{\circ}$. Step-by-step data collection is shown, with a step width of $0.02^{\circ}$ and a counting time of 2 seconds per step. The presence of the peaks is consistent with apatite. $\mathbf{B}$, At scanning electron microscopy, platelike aggregates up to $8 \mu \mathrm{m}$ in size are clearly visible. The aggregates reveal a tabular hexagonal shape consistent with crystals of apatite. (Original magnification, $30,000 \times$.)

explanted from patients. The prevalent involvement of collagen matrix at TEM may be explained by the advanced calcification. The XRPD technique disclosed the presence of the most intense diffraction peaks in keeping with apatite. Quantitative EMPA analysis of in vitro tested bioprostheses shows a $\mathrm{Ca} / \mathrm{P}$ ratio of $4.5: 3$, which is lower than that of pure apatite (5:3) and higher than that of octacalciumphosphate
(4:3). The finding of a $4.5: 3 \mathrm{Ca} / \mathrm{P}$ ratio in the in vitro tested bioprostheses could be explained in terms of rapid coprecipitation of 2 calcium phosphate compounds: apatite and the metastable octacalciumphosphate. ${ }^{19}$ This hypothesis will require further investigation, but the presence of octacalciumphosphate agrees with the de novo precipitation of hydroxyapatite and with the mechanism of the non-energy-requiring $\mathrm{Ca}^{2+}$ 

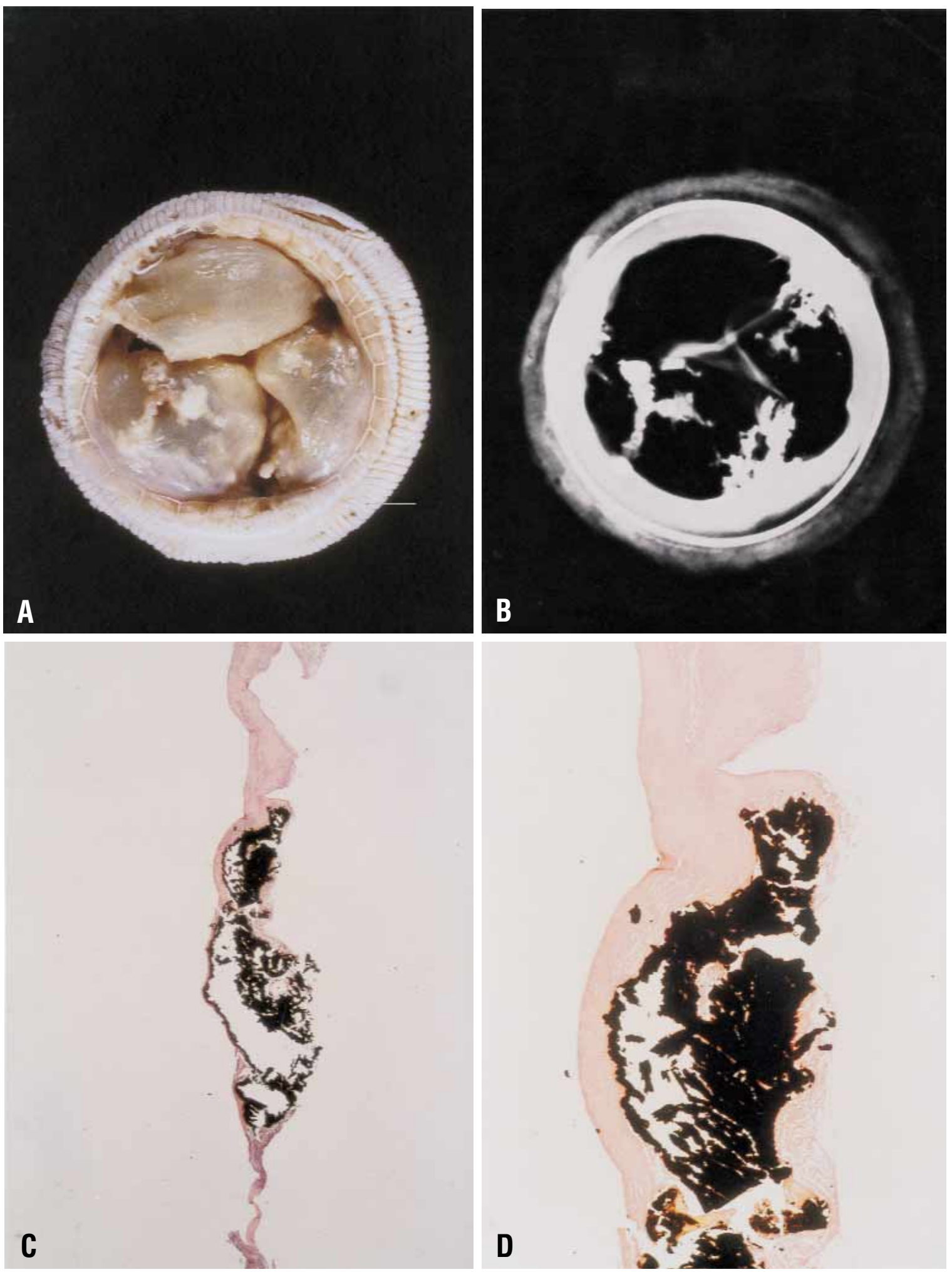

Fig 6. St Jude Medical Bioimplant xenograft in place in human mitral position for 84 months. A, Gross view of the inflow surface with coarse calcification. B, Score 4 calcification at x-ray examination. $\mathbf{C}$, Intrinsic calcification at histology. (Von Kossa stain; original magnification, 12×.) D, Close up of C. (Von Kossa stain; original magnification, 36x.) 


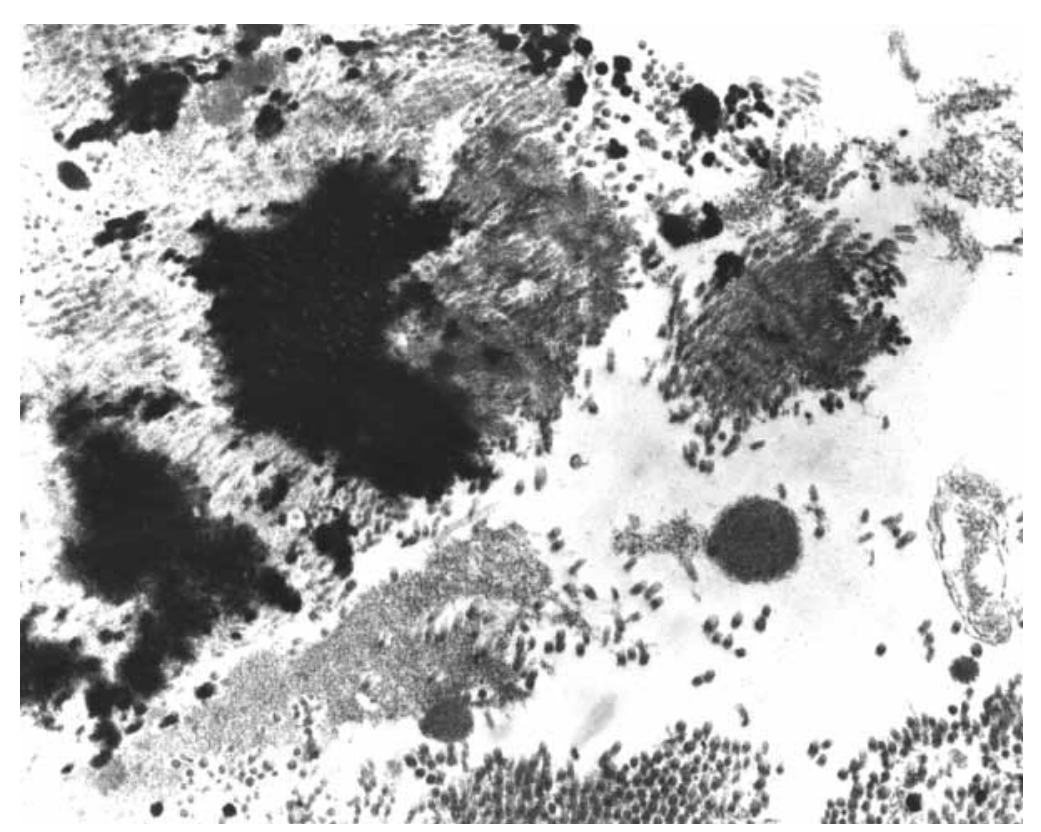

Fig 7. TEM of the same human porcine xenograft shown in Fig 6. Note calcification mostly involving collagen fibers. (Original magnification, 24,000×.)

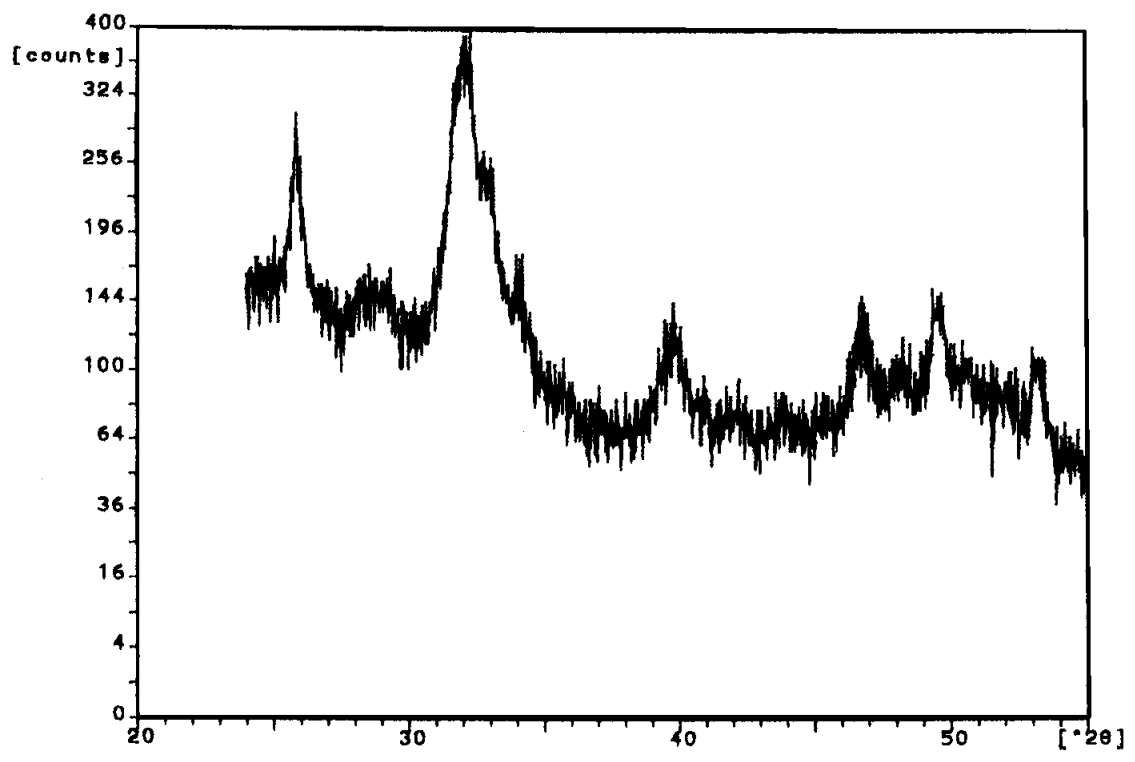

Fig 8. XRPD $\left(\mathrm{CuK} \alpha_{1,2}\right)$ patterns ( $2 \theta$ range, $\left.24^{\circ}-55^{\circ}\right)$ of the same human porcine xenograft as shown in Fig 6 . Stepby-step data collection is shown, with a step width of $0.02^{\circ}$ and a counting time of 2 seconds per step. The presence of the sharp peaks is consistent with massive well-crystallized apatite.

trap by phospholipids, as described in cartilage mineralization. ${ }^{14}$

In vivo test models (subdermal implantation in rats and orthotopic implantation in juvenile sheep) are extensively used, but they show remarkable variability as a result of individual host factors, which render unreliable the results when evaluating anticalcification strategies. ${ }^{20}$ All our explants from in vitro calcification showed severe mineralization and calcium content at atomic absorption spectroscopy of well over $100 \mathrm{mg} / \mathrm{g}$ 
dry weight each. These findings suggest less variability of mineralization in the long term of in vitro testing than that observed in in vivo test models. ${ }^{8,21}$ Thus, the in vitro test model, which allows for calcification of tested valves with identical well-controlled conditions and with the opportunity to directly observe the ongoing calcification process ( $\mathrm{x}$-ray) during the test period, ${ }^{22,23}$ seems to be superior to the in vivo models. The cost of the test device is appealing, amounting to about $\$ 4000$, and the cost during testing is negligible because of the relatively cheap chemical components of the solution (barbital buffer, calcium, and phosphate). Overall, the test compares favorably with rat subcutaneous implants.

In conclusion, bioprosthetic calcification obtained in vitro is similar to that occurring in bioprostheses implanted in vivo. The model may be of value to accelerate the screening of anticalcific agents and may reduce the need for animal experiments. Studies comparing different calcium mitigation treatments are in progress.

We thank Sirio Turco, Agostino Leorin, and Mauro Pagetta for their skillful technical assistance.

Received for publication April 26, 2000; revisions requested July 24, 2000; revisions received Oct 11, 2000; accepted for publication Oct 19, 2000.

Address for reprints: Marialuisa Valente, MD, Department of Pathology, University of Padua Medical School, Via A. Gabelli, 61, 35121 Padova, Italy (E-mail: mvalente@ux1.unipd.it).

\section{REFERENCES}

1. Milano A, Bortolotti U, Talenti E, Valfrè C, Arbustini E, Valente $\mathrm{M}$, et al. Calcific degeneration as the main cause of porcine bioprosthetic valve failure. Am J Cardiol 1984;53:1066-70.

2. Schoen FJ. Cardiac valve prostheses: review of clinical status and contemporary biomaterial issues. J Biomed Mater Res 1987; 21:91-117.

3. Schoen FJ, Levy RJ, Nelson AC, Bernhard WF, Nashef A, Hawley M. Onset and progression of experimental bioprosthetic heart valve calcification. Lab Invest 1985;52:523-32.

4. Valente M, Bortolotti U, Thiene G. Ultrastructural substrates of dystrophic calcification in porcine bioprosthetic valve failure. Am J Pathol 1985;119:12-21.

5. Schoen FJ, Tsao JW, Levy RJ. Calcification of bovine pericardium used in cardiac valve bioprostheses: implications for the mechanisms of bioprosthetic tissue mineralization. Am J Pathol 1986;123:134-45.
6. Bernacca GM, Fisher AC, Wilkinson R, Mackay TG, Wheatley DJ. Calcification and stress distribution in bovine pericardial heart valves. J Biomed Mater Res 1992;26:959-66.

7. Levy RJ. Glutaraldehyde and the calcification mechanism of bioprosthetic heart valves. J Heart Valve Dis 1994;3:101-4.

8. Valente M, Pettenazzo E, Thiene G, Molin GM, Martignago F, De Giorgi G, et al. Detoxified glutaraldehyde cross-linked pericardium: tissue preservation and mineralization mitigation in a subcutaneous rat model. J Heart Valve Dis 1998;7:283-91.

9. Deiwick M, Glasmacher B, Zarubin AM, Reul H, Geiger A, Von Bally G, et al. Quality control of bioprosthetic heart valves by means of holographic interferometry. J Heart Valve Dis 1996;5:441-7

10. Glasmacher B, Deiwick M, Reul H, Knesch H, Keus D, Rau G. A new in vitro test method for calcification of bioprosthetic heart valves. Int J Artif Organs 1997;20:267-71.

11. Starcher BC, Urry DW. Elastin coacervate as a matrix for calcification. Biochem Biophys Res Commun 1973;53:210-6.

12. FDA's heart valve guidance: replacement heart valve guide. 4 th ed. Rockville (MD): US Food and Drug Administration; 1993.

13. Majno G, Joris I. Cells, tissues and disease: principles of general pathology. Cambridge (MA): Blackwell Science; 1996. p. 229.

14. Irving JT, Wuthier RE. Histochemistry and biochemistry of calcification with special reference to the role of lipids. Clin Orthop 1968;56:237-60

15. Anderson HC. Normal and abnormal mineralization in mammals. Trans Am Soc Artif Organs 1981;27:702-7.

16. Giddens DP, Yoganathan AP, Schoen FJ. Prosthetic cardiac valves. Cardiovasc Pathol 1993;2:167S-77S.

17. Bernacca GM, Mackay TG, Wheatley DJ. In vitro calcification of bioprosthetic heart valves: report of a novel method and review of the biochemical factors involved. J Heart Valve Dis 1992;1:115-30.

18. Schoen FJ, Golomb G, Levy RJ. Calcification of bioprosthetic heart valves: a perspective on models. J Heart Valve Dis 1992;1: $110-4$.

19. Cheng PT. Formation of octacalciumphosphate and subsequent transformation to hydroxyapatite at low supersaturation: a model for cartilage calcification. Calcif Tissue Int 1987;40:339-43.

20. Mako WJ, Vesely I. In vivo and in vitro models of calcification in porcine aortic valve cusps. J Heart Valve Dis 1997;6:316-23.

21. Thiene G, Laborde F, Valente M, Gallix P, Talenti E, Calabrese F, et al. Morphological survey of a new pericardial prosthesis (Pericarbon): long-term animal experimental model. Eur J Cardiothorac Surg 1989;3:65-74.

22. Deiwick M, Glasmacher B, Baba HA, Roeder N, Reul H, Von Bally $\mathrm{G}$, et al. In vitro testing of bioprostheses: influence of mechanical stresses and lipids calcification. Ann Thorac Surg 1998;66:S206-11.

23. Fisher AC, Bernacca GM, Mackay TG, Dimitri WR, Wilkinson $\mathrm{R}$, Wheatley DJ. Calcification modelling in artificial heart valves. Int J Artif Organs 1992;15:284-8. 